Iberian Journal of the History of Economic Thought

ISSN-e 2386-5768

\title{
Jovellanos y Adam Smith. Acerca del fenómeno de las influencias en la historia del pensamiento económico
}

Vicent Llombart Rosa $(\dagger)^{1}$

Received: 01/11/2017 / Accepted: 01/11/2017

Resumen. La historiografía suele caracterizar a Gaspar Melchor de Jovellanos como un autor smithiano, en particular al juzgar el Informe de Ley Agraria. El profesor Vicent Llombart rebatía esta asunción en estas páginas, presentadas en un congreso en Gerona de 1997, argumentando que la elaboración del andamiaje analítico de dicho Informe fue anterior a una lectura detenida de La riqueza de las naciones por parte del escritor asturiano, y que la coincidencia con algunos argumentos económicos del escocés fueron la causa probable de la relectura de esta obra tal como aparece manifiesta en sus Diarios.

Palabras clave: Jovellanos; Adam Smith; circulación de las ideas; Ilustración.

[en] Jovellanos and Adam Smith. On the phenomenon of influences in the history of economic thought

\begin{abstract}
Historiography usually distinguishes Gaspar Melchor de Jovellanos as a Smithian author, particularly when judging the Informe de Ley Agraria. Professor Vicent Llombart refuted this assumption in the following pages, presented at a congress in Gerona in 1997, arguing that the elaboration of the analytical scaffolding of this report was prior to a close reading of The Wealth of Nations by the Asturian writer, and that the coincidence with some economic arguments of the Scottish author was the most probable cause of the new reading of this work as it appears manifested in his Diaries.
\end{abstract}

Keywords: Jovellanos; Adam Smith; circulation of ideas; Enlightenment.

JEL Classification: B12, B31

Con frecuencia los historiadores del pensamiento tratamos con demasiada rapidez o de forma un tanto ingenua el complejo fenómeno de la influencia de las ideas o las obras de un autor sobre otro. Existe una cierta tendencia a considerar las citas o referencias a un autor, especialmente cuando es foráneo y conocido, como indicador de influencia y a identificar el concepto de influencia con el de adhesión mimética al sistema del autor influyente o con la simple reproducción de las ideas originales. A menudo no se advierte la multiplicidad de motivos que puede tener un autor para citar los textos de otro, y que varios de tales motivos no serían expresión de una genuina influencia: como ocurre por ejemplo cuando se cita con el fin de ostentar conocimientos bibliográficos o para mostrar apoyos adicionales más elegantes o efectivos de ideas ya formadas con anterioridad o, incluso, para combatir al autor citado o para reutilizar sus ideas con fines bien distintos de los originales. En realidad, sucede que en cuanto pretendemos ser precisos en nuestras afirmaciones el propio concepto de influencia en la historia de las ideas - como en la propia disciplina de la psicología - no tiene un

\footnotetext{
Publicación póstuma de la ponencia inédita presentada por Vicent Llombart al VI Congreso de la Asociación de Historia Económica. Girona, 15 a 17 de septiembre de 1997. Este trabajo formaba parte de un proyecto de investigación financiado por el Ministerio de Educación y Cultura (DGICYT, PS94-0182) y contaba con otra versión anotada que hemos contrastado y refundido. El texto, las notas de pie de página y la bibliografía han sido revisados por Pablo Cervera Ferri, autor de los resúmenes y de las notas del editor.
} 
significado conciso e inequívoco. Deberíamos tener presente que el concepto propio y fuerte de influencia es el de "influencia determinante", es decir un influjo que produce un cambio en el pensamiento del autor que no se hubiera producido en su ausencia. Siempre es difícil precisar tales cambios pues los autores no suelen confesar la forma de escribir y componer sus obras, pero es necesario tener en cuenta ese concepto de influencia determinante para ser más precisos y diferenciarlo de la simple difusión general de las ideas económicas.

Un ejemplo paradigmático de influencia importante que suele manejarse en la historiografía sobre el pensamiento económico español es la que ejerció Adam Smith sobre Jovellanos, en particular sobre su principal obra económica: el Informe de Ley Agraria publicado en 1795 . En un artículo reciente ${ }^{2}$ he intentado analizar con detalle la cuestión de fondo previa para discutir y valorar tal influencia, como es la necesidad de consideración del conjunto de fuentes posibles del Informe. Para un lector infatigable y crítico de abundantes libros de muy distinta procedencia como Jovellanos no es tarea fácil determinar la filiación individualizada de sus ideas ni la suma de fuentes que pudo utilizar para construir su obra. Indiqué en dicho artículo la necesidad de distinguir entre un análisis ex-ante de las fuentes - sobre el conjunto de conocimientos económicos de autor que pueden se relevantes para la redacción de la obra-y un análisis expost de las fuentes una vez se han reflejado en el texto definitivo a través de referencias, notas a pie de página, alusiones explícitas o implícitas e incluso ocultaciones (por lo que pueden existir fuentes invisibles de importancia, como fueron los casos de Cabarrús y Olavide, que posiblemente por razones de prudencia no citó Jovellanos). No repetiré ahora el prolijo análisis de las fuentes; sólo tendré en cuenta sus principales conclusiones a la hora de reconsiderar la relación entre Jovellanos y Smith que también abordé en dicho artículo.

\section{Jovellanos: ¿un economista smithiano?}

La cuestión de la influencia de Adam Smith sobre el pensamiento económico de Jovellanos se ha convertido en un aspecto clave en

Se refiere a Llombart (1996). Se publicó en realidad como capítulo de libro. [Nota del editor]. las interpretaciones modernas de la obra del asturiano. En realidad, esta es una cuestión que no afecta sólo a Jovellanos, sino al conjunto de los economistas españoles de la época de la Ilustración y a las propias categorías que se suelen utilizar para encuadrar el pensamiento de los escritores económicos de aquellos tiempos. El hecho indudable de que La riqueza de las naciones constituya la principal obra económica del siglo XVIII y una de las más influyentes de la historia de la economía, junto con la seducción creciente que ha venido ejerciendo su autor durante más de doscientos años, ha inducido a muchos historiadores no sólo a valorar a los economistas del pasado a partir de una simple (y en ocasiones poco profunda) comparación con el economista escocés, sino incluso a utilizar principalmente a Smith como un elemento divisorio básico en las clasificaciones o encasillamientos a que a menudo se reduce la historia del pensamiento económico del siglo XVIII. En este sentido, ha sido y sigue siendo bastante común, dividir el pensamiento económico de esa centuria en tres escuelas, sistemas o corrientes homogéneas de ideas: el viejo mercantilismo - proveniente del siglo XVII y caracterizado por la doctrina de la balanza comercial y por el intervencionismo y proteccionismo económicos-, la fisiocracia - irradiada desde la Francia de 1760-70 y fundamentada en el Tableau économique, la teoría de la productividad exclusiva de la agricultura y el impuesto único sobre la renta- - y el liberalismo económico smithiano que supondría a partir de 1776 una ruptura y un arrumbamiento de las dos tradiciones anteriores. Este esquema simple y cómodo de usar, muy influido por la propia versión smithiana de la historia del pensamiento -que englobaba todas las ideas anteriores en un sistema mercantil y un sistema agrícola - es el que viene generalmente utilizándose para encasillar en esos tres modelos excluyentes a los abundantes economistas del siglo XVIII, provenientes de diversas tradiciones nacionales europeas y exponentes de ideas en buena parte heterogéneas. En cuanto un autor se resiste al pleno encuadramiento, como ocurre con Jovellanos y con tantos otros, se fuerza el análisis para intentar ajustarlo en lo esencial a una de las plantillas, se eliminan o minimizan los elementos discordantes, y se termina por no apreciar lo que quizá más importaba: lo peculiar, lo distintivo, lo específico en la construcción intelectual del pensador que 
a menudo consistió en una singular combinación de elementos de procedencia plural.

Desde el primer estudio moderno sobre $\mathrm{JO}_{\mathrm{O}}$ vellanos, economista de Jesús Prados Arrarte (1945, reeditado en 1967) hasta los análisis más recientes el enfoque descrito ha estado bien presente, aunque con diferentes y oscilantes desenlaces. El profesor Prados comenzaba y terminaba su estudio pionero subrayando que "Don Gaspar Melchor fue postmercantilista". A esa conclusión llegaba en buena parte por exclusión, tras mostrar - cabe subrayarlo- con amplia documentación y considerable detalle que su pensamiento no se ajustaba ni al patrón fisiocrático ni al smithiano. Como los patrones no se cuestionaban, no encontró otra solución que adoptar el vago término de postmercantilismo para caracterizar las ideas económicas de Jovellanos; término con el que quería significar que el pensamiento del asturiano suponía "variaciones de matiz" sobre la vieja doctrina mercantilista con algunas incrustaciones menores de los fisiócratas y Smith. ${ }^{3}$ En un sentido similar, estudiosos como Martínez Cachero, al comprobar con argumentos bien documentados que Jovellanos no era ni un mercantilista genuino ni un fisiócrata puro ni un seguidor de Adam Smith, optó por clasificarlo entre los "escritores económicos de transición". ${ }^{4}$ Aunque tal calificación, utilizada también por otros historiadores, cuestiona tácitamente la rigidez de los patrones, no supone abordar el fondo del asunto: tanto porque la transición es siempre consustancial a la actividad e historia humanas, como porque en este caso se considera la transición como algo excepcional entre unos patrones predeterminados que siguen manteniéndose como referencia básica.

Sin embargo, frente a estos análisis matizados que tenían la virtud de reconocer la existencia de dificultades en la interpretación del pensamiento económico de Jovellanos de acuerdo con los cánones tradicionales, en la literatura más reciente ha ido ganando terreno el tópico de presentar al Jovellanos del Informe de Ley Agraria como un economista smithiano. Refiriéndonos ahora sólo a algunos de los principales estudios, puede decirse que abrió camino John Polt al insistir en que a partir de un momento no especificado Jovellanos "rechazó los sistemas mercantilista y fisiocrático" para llegar a un acuerdo en lo fundamental con

Prados (1967), caps. I y XXIII.

Martínez Cachero (1976), 82-5.
Smith, "acuerdo fortalecido e incrementado por su repetida lectura de La riqueza de las naciones ".5 Años más tarde y con mayor preocupación por la cronología del fenómeno, Javier Varela encontró en el supuesto "camino hacia el liberalismo" emprendido por Jovellanos una "conversión smithiana" del caminante, simultánea hacia finales de los años ochenta a la disminución de su estima por los economistas españoles. ${ }^{6}$ Por su parte, José Luis Fernández ha considerado que se produjo un deslumbramiento de Jovellanos por las tesis smithianas que le condujo a reelaborar su pensamiento en función de ellas, y Manuel J. González y Rafael Anes han apreciado que el gijonés fue un economista smithiano que aplicó en su Informe lo esencial del núcleo analítico de La riqueza de las naciones. ${ }^{7}$ Por último, en un artículo reciente, Gonzalo Anes (1994) ha considerado que fue gracias a la lectura y el estudio de $L a$ riqueza que Jovellanos pudo ser coherente en sus análisis y propuestas. Ante la reiteración en los estudios recientes por presentar a Jovellanos y su Informe como frutos de la influencia smithiana, quizá sea oportuno aludir a los hechos documentados al respecto antes de abordar las valoraciones sobre los mismos y de proponer una perspectiva general sobre la cuestión.

\section{Los datos documentados}

La primera referencia a Adam Smith entre los papeles de Jovellanos pertenece a agosto de 1790, cuando el embajador español en Londres le remite los tres tomos de La riqueza de las naciones junto con la Filosofía moral de Ferguson y un libro de Burke. ${ }^{8}$ No sabemos con seguridad cual pudo ser el conocimiento anterior, pues la alusión de Julio Somoza de que Jovellanos había extractado y traducido algunas partes de la obra de Smith no se ha podido comprobar. ${ }^{9}$ Pero uno de los principales problemas que plantean los datos efectiva-

Polt (1976), 27 y ss.

Varela (1988), 114-7. Antes, en una influyente obra José Luis Abellán (1981: 564-566) había caracterizado a Jovellanos como un "admirador ferviente de Adam Smith" aunque matizado por su posibilismo y sentido práctico.

Fernández (1991: 214-215); González (1988a: 59-60 y 1988b: 111-112) y R. Anes (1988: 245 y 1994: 111-113).

Estos libros habían sido encargados por Jovellanos al embajador Bernardo del Campo junto con los de Hutcheson y Bacon: "Del marqués del Campo a Jovellanos", Londres, 16 de agosto de 1790, Obras Completas, II, 410-412. Julio Somoza de Montsoriú (1901: 81-125). 
mente documentados sobre la relación entre el escocés y el asturiano es la escasez de referencias a Smith en aquellos escritos de Jovellanos que pretendían tener una trascendencia externa - a través de su publicación o de su difusión como manuscritos por los canales institucionales u oficiales-. En el amplio conjunto de tales escritos, Jovellanos sólo mencionó a Smith en dos notas a pie de página del Informe de Ley Agraria: en la primera ( $\$ 8$ del Informe) acompañando a Varrón y Columela para fundamentar la debilidad del cultivo con esclavos y en la segunda (§ 219) como información sobre la política inglesa favorable a los arrendamientos a largo plazo de las tierras de mayorazgo. Puede comprobarse con facilidad que el contenido de las dos notas es de escasa importancia en la argumentación general del Informe, por lo que las dos referencias explícitas a Smith no desempeñan ningún papel relevante en la obra. Además hay que tener en cuenta que Jovellanos citaba a más de setenta autoridades en apoyo del texto: pensadores de la antigüedad clásica, historiadores, filósofos y moralistas, escritores económicos y políticos, juristas, científicos y hasta literatos y artistas. Las dos citas de Smith deberían contemplarse con relación a ese amplio conjunto de referencias. ${ }^{10}$

No hay más citas de Smith en sus escritos económicos, educativos, históricos o políticos. El apoyo documental que generalmente se aduce para fundamentar el influjo smithiano - además de las posibles analogías textuales o conceptuales a las que después nos referiremos - proviene principalmente de las anotaciones de un escrito íntimo como era su Diario. ${ }^{11}$ Las alusiones al escocés en el mismo aparecen entre mayo y noviembre de 1796. El 25 de mayo anotaba que dos días antes "acabó la lectura de Necker, y [Acebedo, su secretario] empezó a leerme el Smith; va para mí de tercera vez: leí primero la traducción anónima francesa; después el original inglés, que regalé a Pedrayes [la semana anterior]; ahora la traducción de Roucher hecha para las no-

10 En Llombart (1996: 132-123) he expuesto una tabla de las referencias principales del Informe, donde Smith ocupa el lugar catorce por el número de citas.

11 Recordaremos, no obstante, que la primera alusión a Smith entre los papeles de Jovellanos esté contenida en la carta personal del marqués del Campo remitiéndole desde Londres los tres tomos de la quinta edición inglesa de $L a$ riqueza de las naciones (que fue la utilizada en el Informe): "Del marqués del Campo a Jovellanos", Londres, 16 de agosto de 1790, Obras Completas, II, 410-412. tas de Condorcet". ${ }^{12}$ Durante tres meses había estado leyendo intensamente el libro sobre las finanzas francesas de Necker —además de otras obras como las Memorias históricas de Capmany - afirmando al concluirlo que "está sublime sobre la guerra, como filósofo y como economista", y ahora dedicaría otros seis a leer con intensidad a Smith pero sin abandonar otras lecturas simultáneas, como la obra histórica de W. Young, la Political Justice de Godwin, el English system of finance de Thomas Paine y la Vie de M. Turgot de Condorcet traduciendo y extractando las dos últimas-. En dos ocasiones anota elogios a La Riqueza (“iqué admirable cuanto analiza!” y “¡cómo prueba las ventajas del comercio libre con América!"') y al finalizar con el tema escribe: "se concluye la lectura de Smith, y es la cuarta [sic]. Septies repetita placebunt". ${ }^{13}$

¿Cómo valorar estas alusiones del Diario? Tres consideraciones cabe hacer al respecto. En primer lugar, el carácter íntimo de un escrito como el Diario no favorece la precisión de las anotaciones ni permite obtener conclusiones inequívocas sobre la posible influencia de Smith en la obra escrita de Jovellanos - como historiadores de las ideas no nos interesa tanto si el asturiano disfrutó íntimamente con la lectura de Smith sino si éste tuvo influencia en sus escritos económicos y políticos-. En segundo lugar, respecto a las lecturas de Smith a las que alude - que debieron ser tres, aunque en el último párrafo probablemente se equivocó al afirmar que era la cuarta - tampoco sabemos de qué tipo fueron, en especial las dos primeras; en todo caso, queda confirmado que fueron lecturas compartidas con otros muchos libros que pudieron asimismo tener su incidencia. Y, en tercer lugar, de las palabras de Jove-

12 Diario, Obras publicadas e inéditas, BAE, III, 372. Las obras y ediciones a que se refiere Jovellanos son las siguientes: Necker, Jacques : De l'administration des finances de la France, [París], 1784, 3 vols.; Smith, Adam: Recherches sur la nature et les causes de la richesse des nations... Traduit de l'anglois par $M * * *$, La Haye, 177879, 4 vols.; Smith, Adam: An inquiry into the nature and causes of the wealth of nations... The fifth edition, London, 1789, 3 vols.; y Smith, Adam : Recherches sur la nature et les causes de la richesse des nations. Traduites de l'anglois... sur la quatrième édition, par M. Roucher: et suivies d'un volume de notes, par M. le Marquis de Condorcet... Paris, 1790-91, 4 vols. (el volumen anunciado de las notas de Condorcet no llegó a publicarse).

13 Diario, Obras publicadas e inéditas, BAE, III, 357-397. La única alusión adicional a Smith entre los papeles conocidos de Jovellanos se refiere a que estando aprisionado en Bellver en 1804 recibió de un médico mallorquín "la obra de Smith"; cf.: "De Rafael Roselló a Jovellanos", Palma de Mallorca, 6 de agosto de 1804, Obras Completas, IV, 100. 
llanos se deduce que la lectura principal y más profunda de La riqueza de las naciones fue la tercera, la que realizó entre mayo y noviembre de 1796: ¡dos años después de terminado el Informe de Ley Agraria! Conviene insistir, aunque ello debiera haber sido innecesario, en la imposibilidad material de que esa lectura principal influyera de manera alguna en su principal obra económica. Casi me atrevería a apuntar una hipótesis invertida al respecto: ¿no es posible que las propias conclusiones a que llegó Jovellanos en el Informe de Ley Agraria, a partir de un amplio conjunto de fuentes y de un notable esfuerzo personal, le hicieran aumentar su aprecio por Adam Smith y disfrutar con una posterior y detenida lectura de una $R i$ queza de las naciones en la que pudo descubrir diversas coincidencias? De ser así las cosas, en lugar de subrayar la influencia de Smith en el Informe (y menos aún de calificar la obra como smithiana), sería más adecuado destacar la influencia del Informe en la recepción y difusión posteriores de Smith. De todas formas, dejamos abierta para una reflexión posterior la cuestión de si Jovellanos se hizo smithiano con posterioridad al Informe o a 1796.

Otros dos tipos de argumentos se han utilizado en la literatura reciente para presentar a Jovellanos como un economista smithiano: las analogías entre algunas expresiones de los escritos de Jovellanos y las de La riqueza y la adopción de los principios del interés propio y de la libertad económica tomados de Smith como ideas básicas del Informe. Sobre la primera cuestión cabe indicar la improcedencia metodológica de la obtención de conclusiones a partir de comparaciones de frases aisladas y que, además, las comparaciones específicas realizadas - referidas a escritos de 1784 y 1785 - no evidencian en absoluto una influencia smithiana determinante. La primera y curiosa analogía que suele presentarse hace referencia a la defensa de Jovellanos de las leyes de navegación en su "Informe sobre el fomento de la marina mercante" (1784), aunque la argumentación que hace Smith al respecto es sustancialmente distinta a la del asturiano como puso de manifiesto Robert Sidney Smith (1957). La segunda se refiere a la crítica a los gremios expuesta en el "Informe sobre el libre ejercicio de las artes" (1785): pero tampoco las similitudes aludidas son concluyentes dado que por aquellas fechas críticas semejantes estaban muy extendidas en España y en el resto de Europa. En el análisis específico de los efectos perniciosos de los gremios y en las reglas formuladas para su reforma, Jovellanos estaba mucho más próximo a Campomanes que a Smith. Por último, también se ha aludido a la extracción smithiana de la argumentación de Jovellanos sobre la libertad del comercio de granos en los "Apuntes para una memoria" que posiblemente redactó en 1785: pero en este caso sus razonamientos tienen una mayor coincidencia con lo expuesto por Condillac (1776) que con lo sostenido por Smith.

Más compleja e interesante es la discusión sobre el segundo argumento. Es cierto que en el Informe de Ley Agraria existe un elemento general impregnador, ordenador y unificador de su contenido: el principio de que la libre acción del interés privado de los agentes económicos dentro de la esfera de la justicia constituía la fuente principal del progreso agrario. Como corolario del principio insistía una y otra vez Jovellanos en que la acción principal del gobierno no debía consistir en promulgar nuevas leyes dirigistas, sino en "remover los estorbos que se oponían a la libre acción del interés" individual. El problema principal radica en la difícil determinación de si este principio lo había tomado Jovellanos de Smith, pero también en si la aplicación del mismo era similar por ambos autores. Para ilustrar y encuadrar la posible respuesta, que en cualquier caso nunca será taxativa, parecen oportunas las siguientes observaciones. Primero, que las ideas del interés propio y de la libertad económica estaban muy extendidas en la literatura económica inglesa, francesa e italiana del siglo XVIII, por lo que no cabe atribuir una propiedad intelectual exclusiva sobre ellas a Adam Smith, cuya obra según ha insistido Terence Hutchison debería ser vista más como una culminación de un rico y geográficamente plural periodo precedente de unos cien años que como la apertura revolucionaria de una nueva era basada en un paradigma ex novo. ${ }^{14}$ Incluso en la literatura económica española anterior al Informe de Jovellanos pueden encontrarse formulaciones y ecos de tales ideas, que pudieron también servir de apoyo al asturiano. ${ }^{15}$ Segundo, cabe recordar que el principio básico inspirador del Informe ya lo tenía Jovellanos for-

4 Hutchison (1988: 369-371 y 1993: 218). Una exposición sistemática de las ideas del interés propio anteriores a Smith puede verse en M.L. Myers (1983).

5 En especial en las obras de B. Ward, Olavide, Bruna. E, Ramos, Campomanes, Cabarrús... Vid. J. A. Maravall (1991: $169-178$ y 245-269). 
mulado desde 1787 , a raíz de su crítica al documento elaborado por la Junta de Ley Agraria de la Matritense sobre las supuestas cincuenta causas de la decadencia agraria española, y que en aquellos momentos el conocimiento que tenía de Smith parece menos profundo que el adquirido con posterioridad. Tercero, si bien es evidente que existen algunas analogías en el tratamiento del principio del interés propio por parte de ambos autores, es imprescindible señalar que también hay diferencias. Al menos una de ellas es preciso resaltar ahora: mientras Jovellanos afirmaba que era necesario eliminar previamente las leyes que se oponían al interés propio para que éste pudiera actuar, Smith consideraba que el deseo de mejorar la propia condición triunfaba generalmente sobre los obstáculos de las leyes imperfectas. ${ }^{16} \mathrm{Y}$ cuarto, también resulta imprescindible subrayar una diferencia fundamental entre ambos autores en cuanto al alcance del principio de libertad económica. Como analizó el profesor Prados Arrarte, al parecer con tal despliegue de detalles que aún nadie se ha atrevido a contradecirle pormenorizadamente en este punto, el liberalismo económico de Jovellanos se desvanece al traspasar las fronteras nacionales. En el Informe de Ley Agraria - $\mathrm{y}$ en el resto de sus escritos económicos - la libertad económica se circunscribe a los estorbos interiores que frenaban la producción y circulación económicas, dentro de un marco proteccionista respecto al resto del mundo. En ningún momento formula Jovellanos principios librecambistas; es decir, en sus textos nunca llega a defender las ventajas para España de una liberalización de las relaciones económicas internacionales. ¿Puede ser smithiano un texto proteccionista? Al menos tendrá que serlo con muchos matices.

Una cuestión habíamos dejado abierta: ¿se hizo más smithiano Jovellanos después de que en 1796 leyera con detenimiento La riqueza? Un nuevo dato que ha pasado desapercibido en la literatura podemos aducir para proponer una contestación negativa. En 1798 en las memorias pedagógicas redactadas por Jovellanos para la reforma de los estudios que pretendía emprender durante su ministerio de Gracia y Justicia defendía, como ya había hecho con anterioridad ante la Sociedad Económica Asturiana, la necesidad de la enseñanza

16 Puede verse Adam Smith (1776: 310, 480 y 601), donde se subraya ese triunfo del interés propio sobre las trabas legales. de la economía política y proponía una doble combinación de textos para su estudio: por un lado, la obra Sobre el Comercio y el Gobierno considerados con relación recíproca de Condillac junto con las de Uztáriz y Ulloa - estas últimas en lo relativo a los intereses españoles - y, por otro, la Aritmética Política de Arriquíbar y "lo que se extracte de la Industria popular y sus Apéndices, de Herrera, Ward y D. Miguel Suárez: todo acomodado a los asuntos propios". ${ }^{17}$ Jovellanos no recomendaba $L a$ riqueza de Smith que ya estaba traducida al castellano desde 1794, y la selección de libros adoptada no se corresponde con la que cabría esperar de un smithiano. No cabe duda, pues, de que cuatro años después del Informe Jovellanos se mantenía en una posición que podríamos denominar conciliatoria entre los economistas españoles y el pensamiento foráneo, ${ }^{18}$ y su aportación más notable no parecía haber sido el resultado de una iluminación repentina seguida de una conversión a un nuevo sistema que le hubiera hecho romper con sus posiciones anteriores.

Continuar encuadrando el pensamiento económico de Jovellanos y en particular su principal obra - el Informe de Ley Agraria- de acuerdo con el patrón del liberalismo económico smithiano conduce a un camino equívoco, que oculta más de lo que revela y posiblemente impide una percepción realista de la evolución del pensamiento económico en la España del siglo XVIII. Presentar como característica básica del Informe de Jovellanos su ruptura o discontinuidad con los economistas ilustrados españoles anteriores fruto en buena medida de un fuerte influjo smithiano posiblemente sea un error de interpretación, pues no existió ni tal ruptura ni el influjo fue tan nítido

\footnotetext{
"Memorias pedagógicas. Plan para la educación de la nobleza y clases pudientes españolas" (1798), Obras publicadas e inéditas, BAE, V, 327. Al hablar de D. Miguel Suárez se estaba refiriendo a los 12 volúmenes de sus Memorias Instructivas (1778-1791) en las que se publicaron traducidos importantes textos económicos como los de Condillac, Necker y Turgot y abundantes memorias agrícolas.

18 Incluso es posible encontrar los ecos de esta propuesta, aunque sin especificar autores, en las "Bases para la formación de un Plan general de instrucción pública" que Jovellanos compuso como miembro de la Junta Central en 1809 en el que volvía a insistir sobre la necesidad de la enseñanza de la economía política dividida en dos partes: "una que comprenda los principios del comercio considerado con relación al gobierno y tomado de la economía civil, y otra los principios y reglas prácticas de la profesión mercantil", Obras publicadas e inéditas, BAE, I, $272-3$.
} 
e integral. Por el contrario, del análisis conjunto de las fuentes intelectuales del Informe se desprende que La riqueza de las naciones fue uno de los diversos apoyos que utilizó Jovellanos y que este hecho no debe interpretarse de forma excluyente ya que el asturiano mostró en general un deliberado espíritu conciliatorio y abierto a diferentes tradiciones intelectuales. Y del análisis concreto de los obstáculos al progreso agrario y de las reformas propuestas para removerlos que constituyen el contenido principal del texto, se deduce que el Informe era una culminación sistemática de la larga serie de reflexiones agrarias surgidas en la España del XVIII. La inserción plena de Jovellanos en la tradición del pensamiento económico ilustrado español no excluye el reconocimiento de algunos avances en la arquitectura de su construcción intelectual.

El Informe de Ley Agraria de Jovellanos era en definitiva un dictamen dirigido al gobierno a través de la Sociedad Económica Matritense en el que se trataba de aplicar los principios económicos para recomendar la reforma más adecuada de la legislación agraria vigente en España. Apreciar preferentemente la obra a partir de una simple comparación con obras de distinta naturaleza - como La riqueza de las naciones - es un procedimiento inadecuado y hace olvidar que, por su propia finalidad, el Informe estaba estrechamente vinculado a la realidad económica y política española del momento; realidad que debe servir como un elemento importante para su comprensión. El Informe no podía dejar de estar vinculado con el ambiente intelectual de su época, con la atmósfera que se respiraba en España en el terreno de las ideas económicas y políticas en aquella turbulenta década final del siglo de las Luces. Aquellas ideas fueron la referencia principal que debió reconsiderar Jovellanos a la hora de exponer sus propuestas: escogiendo unas, criticando otras, reformulando muchas, introduciendo algunos elementos innovadores, buscando apoyos del pensamiento europeo de procedencia diversa y tratando, en definitiva, de sistematizar y perfeccionar una tradición intelectual.

Por todo ello, me atrevería a sostener que la influencia de Adam Smith en el pensamiento económico de Jovellanos no fue determinante en el sentido que la hemos definido al principio de este ensayo. Quizá la mejor forma de discutir esta cuestión sea la de plantearse el caso contrafactual de si el Informe de Ley Agraria hubiera podido redactarse sin un conocimiento previo de La riqueza de las naciones. Los diferentes argumentos que hemos desarrollado apuntan hacia una contestación afirmativa, hacia la tesis de que La riqueza no fue imprescindible para el nacimiento del Informe. Un argumento adicional en la misma dirección se desprende del proceso de gestación del Informe que ahora sólo comentaremos con brevedad. Cuando Jovellanos recibe el encargo por parte de la Sociedad Económica Matritense de redactar el Informe en 1787, tenía ya esbozadas algunas de las tesis básicas que completará siete años después. En realidad, el encargo lo recibió tras exponer en la reunión de la Junta de Ley Agraria del 17 de septiembre de aquel año su criterio de que los males de la agricultura provenían principalmente de la legislación. ${ }^{19}$ En relación con ello Jovellanos redactó un importante y poco conocido documento de "Comentarios a las causas de la decadencia de la agricultura de España según lo que exponen los Señores de la Junta de Ley Agraria" que constituye con siete años de antelación el embrión del Informe. ${ }^{20}$ Los "Comentarios" no sólo calificaban y analizaban cada una de las cincuenta causas propuestas por los miembros de la Junta, sino que en la última parte del escrito establecían la tesis de que "del examen de las causas ya calificadas se infiere que la decadencia de la agricultura proviene de las leyes", que el "sistema económico de nuestra legislación" constituía el principal obstáculo a la prosperidad agraria. Continuaban insistiendo en la necesidad de establecer un nuevo sistema que asegurase la actuación del principio de libertad económica en el conjunto de las actividades agrarias, pues sólo restableciendo esa libertad se conseguiría el desarrollo de la agricultura. Enumeraban después las leyes específicas que se oponían a la libertad de la propiedad, del trabajo, del comercio y de la industria,

\footnotetext{
G. Anes (1969: 120-121).

L. Domergue (1971: apéndice III, 297-305) publicó el documento como dos manuscritos separados de Jovellanos. En la edición que preparamos del Informe y otros escritos económicos del asturiano* lo publicamos en forma integrada y realizamos un estudio detallado sobre este documento fundamental en la génesis del Informe.

* Vicent Llombart estaba por entonces preparando la obra que aparecería en 2000: Gaspar Melchor de Jovellanos. Escritos económicos. Estudio introductorio de Vicent Llombart. Madrid: Real Academia de Ciencias Morales y Políticas, Ministerio de Economía y Hacienda, Instituto de Estudios Fiscales, Fundación ICO, Clásicos del Pensamiento Económico Español, nueva época. Prólogo de Enrique Fuentes Quintana. [Nota del editor].
} 
enumeración que correspondía básicamente al contenido de los estorbos políticos $-\mathrm{O}$ derivados de la legislación - que presentará en la primera y más extensa parte del Informe de Ley Agraria. Así pues, el conjunto del documento contenía un esbozo de la tesis básica del Informe y un esquema de la principal clase de causas del atraso agrario; todo ello en 1787 y a partir de la reelaboración y discusión crítica de las cincuenta "causas de la decadencia" agraria propuestas por los miembros de la Junta. Existía también una línea básica de continuidad entre el análisis y la selección de causas específicas de Jovellanos y lo que habían mantenido Olavide y Campomanes años antes, aunque éstos no fueran tan lejos en la libertad de los arriendos que reclamaba el gijonés. En definitiva, fue el embrión de 1787, completado por los principios de "libertad, luces y auxilios" como fundamento de la actuación del gobierno que estableció en $1789,{ }^{21}$ el que iría adquiriendo cuerpo y rasgos definitivos en el proceso de redacción desarrollado entre 1792 y 1794.

Ese fue en síntesis el proceso intelectual que llevó a Jovellanos a componer el Informe de Ley Agraria y en dicho proceso La riqueza de las naciones - una obra, repito, de muy distinta naturaleza - no parece que desempeñase un papel decisivo; es decir, no cabe atribuirle un papel determinante.

21 Ese lema lo expuso en los dos escritos siguientes: "Dictamen sobre el embarque de paños extranjeros" (1789) e "Informe sobre un nuevo método para la hilaza de la seda" (1789), Obras publicadas e inéditas, BAE, II, L, 74 y 69-70. 


\section{Bibliografía}

Abellán, J.L. 1981. Historia crítica del pensamiento español, 3. Del Barroco a la Ilustración, Madrid: Espasa-Calpe.

Andrés Álvarez, V. 1955 Prólogo a la edición de Jovellanos, Informe sobre la Ley Agraria (1795). Madrid: Instituto de Estudios Políticos.

Anes, G. 1969. Economía e "Ilustración” en la España del siglo XVIII. Barcelona: Ariel.

- 1990. Estudio preliminar a la edición de Informes en el Expediente de Ley Agraria. Madrid: Instituto de Estudios Fiscales.

- 1994. "La Ley Agraria en la España de las Luces". Cuadernos de Información Económica (92-93), noviembre-diciembre, 197-214.

Anes, R. 1988. "Economía y pensamiento económico en España". En Miguel Artola (dir.), Enciclopedia de Historia de España, III. Madrid: Alianza, 213-271.

- 1994. "Jovellanos, economista" en Economía y empresa en Asturias, Homenaje a Ignacio Herrero, Marqués de Aledo. Madrid: Civitas 105-121.

Astigarraga, J. y Barrenechea, J.M. 1987. Estudio preliminar a la edición de Nicolás de Arriquíbar, Recreación política. Reflexiones sobre el Amigo de los Hombres... (1779). Bilbao: Instituto Vasco de Estadística, 9-57.

Baras, F. 1993. El reformismo político de Jovellanos. Zaragoza: Universidad de Zaragoza.

Barrenechea, J.M. 1984. Valentín de Foronda, reformador y economista ilustrado. Vitoria: Diputación Foral de Álava.

Cabarrús, F. 1956 [1781] Memoria para la formación de un Banco Nacional... Reedición en Moneda y Crédito (56), marzo 1956, 132-44.

- 1786. Elogio del Excelentísimo Señor Conde de Gausa. Madrid: Viuda de Ibarra.

- 1789. Elogio de Carlos III, Rey de España y de las Indias. Madrid: Antonio de Sancha.

- 1974 [1808] Cartas sobre los obstáculos que la naturaleza, la opinión y las leyes oponen a la felicidad pública. Edición de J.A. Maravall. Madrid: Castellote.

Cantillon, R. 1950 [1755] Ensayo sobre la naturaleza del comercio en general. Edición española de M. Sánchez Sarto, México: F.C.E.

Castro, J.F. 1770. Discursos críticos sobre las leyes y sus intérpretes; incertidumbres y detrimentos de los mayorazgos... Madrid: Joaquín Ibarra.

Cicilia Coello, J. 1780. "Memoria premiada... leída en Junta de 29 de marzo de 1777”. En Memorias de la Sociedad Económica, I. Madrid: Antonio de Sancha.

Clément, J.-P. 1980. Las lecturas de Jovellanos (Ensayo de una reconstitución de su biblioteca). Oviedo: Instituto de Estudios Asturianos.

Colmeiro, M.1965 [1863] Historia de la economía política en España. Edición de G. Anes, Madrid: Taurus, Madrid, II vols.

Condillac, E.B. de 1776. Sobre el Comercio y el Gobierno considerados en su relación recíproca. Edición española de Miguel G. Suárez (ed.), Memorias instructivas y curiosas sobre Agricultura, Comercio, Industria, Economía... Madrid: Pedro Marín, 1778-80, III, 219-386 y IV, 3-116.

Defourneaux, M. 1959. Pablo de Olavide ou l'afrancesado. Paris: Presses Universitaires de France.

Domergue, L. 1971. Jovellanos a la Société Économique des Amis du Pays de Madrid (1778-1795). Toulouse: Université de Toulouse.

Dopico, F. 1978. A ilustración e a sociedade galega. Vigo: Galaxia.

Estapé, F. 1971. Ensayos sobre historia del pensamiento económico. Barcelona: Ariel.

Fernández Álvarez, M. 1988. Jovellanos. Un hombre de nuestro tiempo. Madrid: Espasa-Calpe.

Fernández Fernández, J.L. 1991. Jovellanos: antropología y teoría de la sociedad. Madrid; Universidad Pontificia Comillas.

Floridablanca, J. Moñino, conde de. 1982 [1787] Instrucción reservada sobre la Junta de Estado, edición de Joaquín Ruiz Alamán, Escritos políticos Murcia: Academia Alfonso X el Sabio.

Foronda, V. de 1789-1794. Cartas sobre los asuntos más exquisitos de la Economía-Política, y sobre las leyes Criminales. Madrid: Manuel González, II vols.

González, M.J. 1988a. "El progreso del conocimiento económico en la España Ilustrada". Moneda y Crédito (187) 35-60.

- 1988b. "Campomanes y Jovellanos ante el marco institucional de la economía de mercado", Información Comercial Española (656), 103-113. 
Hutchison, T. 1988. Before Adam Smith. The Emergence of Political Economy, 1662-1776. Oxford: Basil Blackwell.

- 1993. Review of "Jacob Viner, Essays on the Intellectual History of Economics (1991)", The European Journal of the History of Economic Thought (1:1), 216-220.

Jovellanos, G.M. de (1789) Elogio de Carlos Tercero. Leído a la Real Sociedad de Madrid... Madrid: Viuda de Ibarra.

- 1795. Informe de la Sociedad Económica de esta Corte al Real y Supremo Consejo de Castilla en el Expediente de Ley Agraria, Extendido por su individuo de número el Sr D. Gaspar Melchor de Jovellanos, a nombre de la Junta encargada de su formación, y con arreglo a sus opiniones. Madrid: Sancha.

- 1858-1956. Obras publicadas e inéditas. Madrid: Biblioteca de Autores Españoles, V vols.

— 1984-1994. Obras Completas. Edición de José Miguel Caso González. Oviedo: Centro de Estudios del Siglo XVIII, VI vols.

Llombart, V. 1992) Campomanes, economista y politico de Carlos III. Madrid: Alianza.

— 1996. "El Informe de Ley Agraria y su autor en la historia del pensamiento económico". En Á. García Sanz y J. Sanz (eds.): Reformas y política agraria en la historia de España. Madrid: Ministerio de Agricultura, 105-519.

Lluch, E. 1973. El pensament econòmic a Catalunya (1760-1840). Barcelona: Edicions 62.

Maravall, J.A. 1991. Estudios de la historia del pensamiento español (siglo XVIII). Madrid: Mondadori.

Martínez Cachero, L.A. 1976. Economistas y hacendistas asturianos. Gijón: Ayalga.

Myers, M.L. 1983. The soul of modern economic man. Ideas of self-interest from Thomas Hobbes to Adam Smith. Chicago: The University of Chicago Press.

Naharro, J.M. 1947. "Jovellanos y algunos problemas de la historiografía económica" Moneda y Crédito (20), marzo, 65-71.

[Necker, J.] 1776. Sur la législation et le commerce des grains. Paris: Pissot.

Perdices de Blas, L. 1992. Pablo de Olavide (1725-1803) el ilustrado. Madrid: Editorial Complutense.

Pereyra, L.M. 1788. Reflexiones sobre la Ley Agraria de que se está tratando en el Consejo. Madrid: s.i.

Polt, J. 1976. "El pensamiento económico de Jovellanos, y sus fuentes inglesas". Información Comercial Española (512), abril, 23-56.

Prados Arrarte, J. 1967. Jovellanos, economista. Madrid: Taurus.

[Ramos, E.] Muñoz, A. 1769. Discurso sobre economía política. Madrid: Joaquín Ibarra.

Rick, L. 1977. Bibliografia crítica de Jovellanos (1901-1976). Oviedo: Cátedra Feijoo.

Sánchez Espinosa, G.1994. "Un paradigma de lectura ilustrada”. En El libro ilustrado. Jovellanos, lector y educador. Madrid: Real Academia de Bellas Artes de San Fernando 33-59.

Schumpeter, J.A. 1971. Historia del análisis económico. Barcelona: Ariel.

Sisternes y Feliú, M. 1993 [1786] Idea de la Ley Agraria Española. Edición de Vicent Llombart. Barcelona: Alta Fulla.

Smith, A. 1776. Investigación sobre la naturaleza y causas de la riqueza de las naciones. Edición castellana de Gabriel Franco. México: F.C.E.

Smith, R.S. 1957. "La 'Riqueza de las Naciones' en España e Hispano-América, 1780-1830”. Revista de Economía Política (VIII: 3), 1215-1253.

Sociedad Económica Matritense. 1795. Memorias de la Sociedad Económica. Madrid: Sancha, tomo V.

Somoza de Montsoriú, J. 1901. Inventario de un jovellanista. Madrid: s.i.

Suárez, M.G. (ed.) 1778-91. Memorias instructivas y curiosas sobre Agricultura, Comercio, Industria, Economía... Madrid: Pedro Marín.

Varela, J. 1988, Jovellanos. Madrid: Alianza.

Ward, B. 1779. Proyecto económico... escrito en el año de 1762. Madrid: Viuda de Ibarra. 